\title{
Poly- $\beta$-hydroxybutyrate Production by Methylosinus trichosporium OB3b at Different Gas-phase Conditions
}

\author{
Tingting Zhang ${ }^{1}$, Jiti Zhou ${ }^{2}$, Xiaowei Wang ${ }^{1, *}$, Yu Zhang ${ }^{2}$ \\ ${ }^{1}$ School of Chemical Engineering and Energy, Zhengzhou University, Zhengzhou, China \\ ${ }^{2}$ Key Laboratory of Industrial Ecology and Environmental Engineering, School of Environmental Science and \\ Technology, Dalian University of Technology, Dalian, China \\ ${ }^{*}$ Corresponding author: Xiaowei Wang, School of Chemical Engineering and Energy, Zhengzhou University, Zhengzhou, China. E-mail: \\ xiaoweiwang@zzu.edu.cn
}

\begin{abstract}
Background: The utilization of methane for production of Poly- $\beta$-hydroxybutyrate (PHB) not only cuts the emissions of greenhouse gases but also greatly reduces $\mathrm{PHB}$ production cost.

Objectives: The aim of this study was to determine the effects of gas-phase conditions on PHB production by Methylosinus trichosporium $\mathrm{OB}_{3} \mathrm{~b}$.

Materials and Methods: Bacterial cultivation and PHB production were conducted in a series of sealed serum bottles. Nitrogen-free mineral salts medium was used to induce PHB production in the presence or absence of $\mathrm{N}_{2}$ in the headspace.

Results: In the absence of $\mathrm{N}_{2}$, the highest PHB content (i.e., 52.9\% of the dry cell weight with a PHB concentration of $814.3 \mathrm{mg} . \mathrm{L}^{-1}$ ) was obtained at a ratio of $\mathrm{CH}_{4}: \mathrm{O}_{2}=2: 1$. Further study at different $\mathrm{O}_{2}$ concentrations with a fixed $\mathrm{CH}_{4}$ partial pressure in absence of $\mathrm{N}_{2}$ showed that PHB accumulation by methanotroph could be tolerated high oxygen partial pressure and its respond to the variation of the oxygen concentration depends on the methane partial pressure. In presence of $\mathrm{N}_{2}$, with headspace gas replenished only when oxygen was almost depleted, the degradation of intracellular PHB has appeared. In the regimen of updating headspace gas at the point when the PHB content began to decrease, the highest PHB content (i.e., 55.5\% of the dry cell weight with 901.8 mg.L - $^{-1}$ PHB concentration and 12.5 mg. $\mathrm{L}^{-1} \cdot \mathrm{h}^{-1} \mathrm{PHB}$ productivity) was obtained at $0.2 \mathrm{~atm} \mathrm{O}_{2}$ and $\mathrm{PHB}$ accumulation was depressed with an oxygen concentration greater than $0.3 \mathrm{~atm}$.

Conclusions: The methanotroph responses differentially to the increase in the oxygen partial pressure with regard to $\mathrm{PHB}$ accumulation either in the presence or in the absence of $\mathrm{N} 2$.
\end{abstract}

Keywords: Methylosinus trichosporium, Nitrogen Fixation, poly-beta-hydroxybutyrate

\section{Background}

Polyhydroxyalkanoates (PHAs) have attracted an increasing attention as an alternative to the traditional plastics, among which Poly- $\beta$-hydroxybutyrate (PHB) is the most widely studied and best-characterized homopolymer (1). However, the expansion of PHB utilization has been restrained due to their high production cost. Consequently, many research groups have devoted themselves to the development of the inexpensive feedstock and low-cost extraction methods. Techno-economic studies have shown that approximately $30-50 \%$ of the PHB production cost is mainly attributed to the expensive carbon sources (2). So, it could be greatly reduced if the waste organic carbon is used as an inexpensive and renewable feedstock, such as $\mathrm{H} 2$, methanol and cane molasses (1, 3-7). Methane, which is abundantly available during fossil fuels extraction and organic waste of the anaerobic degradation process, accounts for $20 \%$ of the worldwide greenhouse gas (GHG) emissions (8)and the global atmospheric methane ratio is increasing at an annual average of $1 \%(9)$. Although some measures have to be taken in order to increase methane solubility and eliminate the possibility of the explosion during $\mathrm{PHB}$ production from methane, it has been estimated that using waste methane as feedstock might reduce the cost of PHB by approximately 30-35\%(10). As well, PHB production from biogas discharged by the existing landfills and anaerobic digesters could theoretically replace $20-30 \%$ of the total plastics annual market (11). Methanotrophs, which utilize methane as the sole carbon source, mainly consist of two groups, type I and II, with different pathways, the ribulose monophosphate 
(RuMP) pathway and the serine pathway, to complete carbon assimilation (12). PHB production has been reported to be restricted to type II genera (13), among which Methylocystis and Methylosinus are the most documented. Both methane and oxygen are important for methanotrophs (2)and variations of their partial pressure are likely to affect the activities and metabolisms of the methanotrophs. PHB are generally synthesized by microorganism under nutrient-limiting conditions and are consumed as a source of reducing equivalent under nutrient-sufficient conditions (12). Nitrogen deficiency is one of the most common ways to trigger the accumulation of PHB (14). The ability to fix molecular nitrogen has been reported to present in all type II genera (13). Methanotrophs can utilize $\mathrm{N}_{2}$ as a sole nitrogen source for growth (15). It has been reported that Methylosinus trichosporium $\mathrm{OB}_{3} \mathrm{~b}$ grew slowly and accumulated about $6 \% \mathrm{PHB}$ under $\mathrm{N}_{2}$-fixing conditions (16). Shah et al. suggested that only $10 \%$ $\mathrm{PHB}$ was produced by $M$. trichosporium $\mathrm{OB}_{3} \mathrm{~b}$ when the mixtures of methane and air were supplied as substrate. However, after air was switched to pure oxygen with the same oxygen flux, the content of PHB was increased to $45 \%$ (17). It is obvious that the presence of $\mathrm{N}_{2}$ could affect the PHB accumulation of the methanotrophs. Nevertheless, the accumulation of PHB by methanotrophs is always stimulated by removing the liquid medium nitrogen source in the previous studies $(9,13-15,17)$. There is a little detailed-information on the impact of $\mathrm{N} 2$ on $\mathrm{PHB}$ production by methanotrophs.

In addition, whether methane is collected from natural gas or biogas, it is inevitable that some $\mathrm{N}_{2}$ would be introduced and the purification is costly. So, it is meaningful to examine how $\mathrm{N}_{2}$ affects the $\mathrm{PHB}$ synthesis ability of the methanotrophs. It has been suggested that nitrogenase activity of the methanotrophs is sensitive to the oxygen partial pressure $(13,15-18)$. Therefore, the effect of $\mathrm{N}_{2}$ on the $\mathrm{PHB}$ synthesis ability of methanotrophs is probably $\mathrm{O}_{2}$ dependent. If a high content of PHB could also be produced in the presence of $\mathrm{N}_{2}$, the requirement for the purity of the methane and oxygen would be greatly reduced. As a result, the $\mathrm{PHB}$ production cost attributed to the substrate could be further reduced.

\section{Objectives}

In order to determine how PHB production of $M$. trichosporium $\mathrm{OB}_{3} \mathrm{~b}$ was affected by the gas-phase conditions in the absence and presence of $\mathrm{N}_{2}$ and explore the possibility of accumulating high content $\mathrm{PHB}$ in presence of $\mathrm{N}_{2}$, this study was performed in two steps. Firstly, it was investigated how PHB accumulation of methanotroph was affected by the variations of the oxygen and methane partial pressure in the absence of $\mathrm{N}_{2}$, and secondly, the effect of the presence of $\mathrm{N}_{2}$ on PHB synthesis was evaluated at different oxygen concentrations in two different headspace gas replenishment regimes.

\section{Materials and Methods}

\subsection{Microorganisms and Culture Conditions}

M. trichosporium $\mathrm{OB}_{3} \mathrm{~b}$ was kindly provided by $M$. Kalyuzhnaya (Lidstrom laboratory, University of Washington) and used throughout this study. $M$. trichosporium $\mathrm{OB}_{3} \mathrm{~b}$ was cultivated in the nitrate minimal salt (NMS) containing (per liter) $\mathrm{KH}_{2} \mathrm{PO}_{4} 0.272 \mathrm{~g}$, $\mathrm{Na}_{2} \mathrm{HPO}_{4} \cdot 12 \mathrm{H}_{2} \mathrm{O} 2.868 \mathrm{~g}, \mathrm{KNO}_{3} 0.10 \mathrm{~g}, \mathrm{MgSO}_{4} \cdot 7 \mathrm{H}_{2} \mathrm{O}$ $0.10 \mathrm{~g}, \mathrm{CaCl}_{2} \cdot 6 \mathrm{H}_{2} \mathrm{O} 0.20 \mathrm{~g}$ and $2 \mathrm{~mL}$ of trace element solutions. The trace element solution was composed of (per 100mL): Na-EDTA 25 mg; $\mathrm{FeSO}_{4} \cdot 7 \mathrm{H}_{2} \mathrm{O} 50 \mathrm{mg}$; Fe-EDTA $38 \mathrm{mg}$; $\mathrm{ZnSO}_{4} \cdot 7 \mathrm{H}_{2} \mathrm{O} 40 \mathrm{mg}$; Cu-EDTA 10 mg; $\mathrm{H}_{3} \mathrm{BO}_{3} \quad 1.5 \mathrm{mg} ; \mathrm{MnCl}_{2} \cdot 4 \mathrm{H}_{2} \mathrm{O} 2 \mathrm{mg}$; $\mathrm{Na}_{2} \mathrm{MoO}_{4} \cdot 2 \mathrm{H}_{2} \mathrm{O} \quad 26 \mathrm{mg} ; \quad \mathrm{CuCl}_{2} \cdot 2 \mathrm{H}_{2} \mathrm{O} \quad 30 \mathrm{mg}$; $\mathrm{NiCl}_{2} \cdot 6 \mathrm{H}_{2} \mathrm{O} 1 \mathrm{mg} ; \mathrm{CoCl}_{2} \cdot 6 \mathrm{H}_{2} \mathrm{O} 5 \mathrm{mg}$. The initial pH of the medium was adjusted to 6.8 applying $1 \mathrm{M}$ sodium hydroxide (19). An amount of $100 \mathrm{~mL}$ of the NMS medium and $5 \mathrm{~mL}$ of culture inoculums was introduced into a series of $300 \mathrm{~mL}$ serum bottles which were capped with butyl rubber stoppers and screw top. Cultures were grown at $30^{\circ} \mathrm{C}$ on the orbital shakers at $150 \mathrm{rpm}$ under a $\mathrm{CH} 4 / \mathrm{O} 2$ gas mixture $(1: 1, \mathrm{v} / \mathrm{v})$. Headspace gas was replenished every $24 \mathrm{~h}$ by being subjected twice to the vacuum and replenished with the same gas mixture $(\mathrm{CH} 4 / \mathrm{O} 2$ at a ratio of $1: 1 \mathrm{v} / \mathrm{v})$ to maintain a sufficient amount of the oxygen. The cell growth was monitored by measuring the gaseous composition in the headspace along with monitoring the optical density at $660 \mathrm{~nm}$ (V560, Jasco International Co., Ltd., Japan) which was correlated with dry cell mass measured after lyophilizationfor $24 \mathrm{~h}$.

\subsection{PHB Production Studies}

The nitrogen-free mineral salts (NFMS) medium, which was identical to NMS medium except for the addition of $0 \mathrm{mM} \mathrm{KNO}_{3}$ to NFMS medium, was used to induce $\mathrm{PHB}$ production. Cell suspensions were harvested after about $5 \mathrm{~d}$ post-cultivation, washed twice with NFMS medium, and re-suspended in NFMS medium $\left(\mathrm{OD}_{660}\right.$ of $\left.1.5 \pm 0.05\right)$. Where after, the cell resuspension solution was divided by transferring $15 \mathrm{~mL}$ aliquots into a series of the $125 \mathrm{~mL}$ serum bottles. The serum bottles were capped with butyl rubber stoppers and screw top

The effect of the gas-phase conditions on the PHB production were first conducted without $\mathrm{N}_{2}$, in which the headspace gas was renewed at every $24 \mathrm{~h}$ for $72 \mathrm{~h}$ to ensure the sufficient gas substrates. To study the effect of the applied ratio of the methane to that of oxygen at a constant pressure and in the absence of $\mathrm{N}_{2}$, the headspace gas was refreshed by being subjected to the vacuum twice, replenished with a mixture of the methane and oxygen $\left(\mathrm{CH}_{4} / \mathrm{O}_{2}\right.$; at the ratio of 3:1, 2:1, $1: 1,1: 2$, and $1: 3 \mathrm{v} / \mathrm{v}$, respectively) to restore an ambient 
atmospheric pressure. To elucidate the effect of different oxygen concentrations at a pressure of $0.5 \mathrm{~atm}$ $\mathrm{CH}_{4}$ without $\mathrm{N}_{2}$, the headspace was first vacuumed, then methane was fed to a partial pressure of $0.5 \mathrm{~atm}$ followed by the addition of oxygen with the different partial pressures (oxygen partial pressure $=0.25,0.33,0.5,0.67$, and $0.75 \mathrm{~atm}$, respectively). At last, helium was added to make sure that the same total pressure was reached in each bottle. The replenishment operation was repeated twice each time. In addition, the oxygen concentration effect (i.e., 0.2-0.6 atm, respectively) on $\mathrm{PHB}$ production was also conducted at 0.2 atm $\mathrm{CH}_{4}$ to explore whether it was varied at the different methane concentrations.

For demonstrating the coupled effect of molecular nitrogen as well as different oxygen concentrations on PHB synthesis in two different headspace gas replenishment regimes, the headspace was first subjected to the vacuum, then methane was fed to the headspace at a partial pressure of $0.5 \mathrm{~atm}$, oxygen at the partial pressure ranging from 0.1 atmto 0.5 atm, and helium was added to restore an ambient atmospheric pressure. At last $\mathrm{N}_{2}$ was fed to the headspace at a pressure of $0.3 \mathrm{~atm}$ applying a gas-tight syringe. In the first replenishment regimen, the headspaces gas was refreshed when the concentration of oxygen was below $5 \%(\mathrm{v} / \mathrm{v})$. In the other regimen, the headspace gas was renovated every $12 \mathrm{~h}$ to inhibit the degradation of intracellular PHB.

All serum bottles were incubated at $30^{\circ} \mathrm{C}$ on the orbital shakers at $150 \mathrm{rpm}$. The initial gaseous compositions were determined and the variations were monitored periodically. Duplicate serum bottles were sacrificed periodically for $72 \mathrm{~h}$. The $10 \mathrm{~mL}$ cell suspensions were subjected to the centrifugation at $4{ }^{\circ} \mathrm{C}$, washed twice with deionized water, lyophilized, and weighed before analysis of PHB.

\subsection{Analytical Methods}

The percent $\mathrm{PHB}$ was analyzed by a gas chromatography (GC7890 II, Techcomp limited, China) equipped with a flame ionization detector (FID) after digestion of the freeze-dried cell pellets (20). The headspace gas composition was determined by a gas chromatography (GC7900, Techcomp limited, China) equipped with a thermal conductivity detector. As well, statistical analyses were performed by PASW statistics release 18.0.0 (SPSS Inc., Chicago, Illinois). Spearman's rank correlation test was employed to determine the significance. $\rho$ represents Spearman's correlation coefficient, $\mathrm{n}$ represents the number of points used, and Prepresents the significance.

\section{Results}

4.1. PHB Production with Different Ratios of Methane to Oxygen at Constant Pressure in the Absence of $\mathrm{N}_{2}$
The changes of the percent $\mathrm{PHB}$ at different $\mathrm{CH}_{4}: \mathrm{O}_{2}$ ratios are illustrated in Figure 1. There was no obvious distinction in the $\mathrm{PHB}$ content among each ratio of methane to oxygen in the first $24 \mathrm{~h}$. After that, a PHB content of $\mathrm{CH}_{4}: \mathrm{O}_{2}=1: 3$ was the first to reach a plateau with a maximal $\mathrm{PHB}$ content of $35.2 \%$, successively followed by $\mathrm{CH}_{4}: \mathrm{O}_{2}=1: 2(40.7 \%), \mathrm{CH}_{4}: \mathrm{O}_{2}=3: 1$ (44.4\%), $\mathrm{CH}_{4}: \mathrm{O}_{2}=1: 1$ (49.5\%), and $\mathrm{CH}_{4}: \mathrm{O}_{2}=2: 1$ (52.9\%). It was obvious that with an increase in $\mathrm{CH}_{4}: \mathrm{O}_{2}$ ratio from $1: 3$ to $2: 1$, gradually a higher maximal $\mathrm{PHB}$ content was obtained. Afterwards, the maximal content of $\mathrm{PHB}$ was decreased when the ratio was further increased to $3: 1(\rho=0.689, \mathrm{n}=10, \mathrm{P}=0.027)$. The maximal $\mathrm{PHB}$ concentration and $\mathrm{PHB}$ productivity at $\mathrm{CH}_{4}: \mathrm{O}_{2}=2: 1$ were $814.3 \mathrm{mg} \cdot \mathrm{L}^{-1}$ and $11.3 \mathrm{mg} \cdot \mathrm{L}^{-1} \cdot \mathrm{h}^{-1}$ respectively.

4.2. PHB Synthesis with Different Oxygen Concentrations at the Fixed Methane Partial Pressures in Absence of $\mathrm{N}_{2}$

In order to determine how oxygen partial pressure influences PHB production of the methanotrophs, the experiments were conducted at the two different methane partial pressures. Figure 2 presents the variations of $\mathrm{PHB}$ content with different oxygen dosages at $0.5 \mathrm{~atm}$ of $\mathrm{CH}_{4}$. It is noteworthy that the PHB synthesis ability of the Methylosinus trichosporium $\mathrm{OB} 3 \mathrm{~b}$ was limited at $0.25 \mathrm{~atm} \mathrm{O}_{2}$. When oxygen partial pressure was successively increased to $0.33,0.5,0.67$ and $0.75 \mathrm{~atm}$, the maximal contents were $41.5 \%, 48.9 \%$, $51.5 \%$ and $52.3 \%$, respectively. The accumulation of PHB was promoted by the higher oxygen concentration $(\rho=0.886, n=10, P=0.001)$. When the partial pressure of the oxygen was as high as $0.75 \mathrm{~atm}$ the conditions was still favorable for PHB synthesis, showing no inhibition. The PHB production at $0.2 \mathrm{~atm} \mathrm{CH}_{4}$ is illustrated in Figure 3. Similarly, the PHB accumulation of the methanotroph was also limited at low oxygen concentration $\left(0.2 \mathrm{atmO}_{2}\right)$. However, unlike the tests with $0.5 \mathrm{~atm} \mathrm{CH}_{4}$, the bacteria accumulated a higher content of PHB at $0.3(38.2 \%)$ and $0.4 \mathrm{~atm} \mathrm{O}_{2}(40.9 \%)$ $(\rho=0.837, \mathrm{n}=6, \mathrm{P}=0.038)$ and the maximal PHB content was greatly decreased by $26.4 \%$ when oxygen partial pressure was further increased to $0.6 \mathrm{~atm}$. It was obvious that PHB production of the methanotroph was strongly dependent on the oxygen concentration and the response to the variation of the oxygen concentration varied at different methane partial pressures, accordingly.

4.3. Coupled Effects of Molecular Nitrogen and Different Oxygen Concentration on the PHB Synthesis in two Different Headspace Gas Replenishment Regimens

In the first headspace gas replenishment regime, the headspace gas was refilled only when oxygen was almost depleted. The intracellular PHB contents in this regimen along with oxygen consumption curve are 
plotted in Figur $\mathbf{4 a}$ and $\mathbf{4 b}$. For an oxygen partial pressure of $0.1 \mathrm{~atm}, \mathrm{PHB}$ content reached the plateau in $7 \mathrm{~h}$ with a value of $5.5 \%$. After the first oxygen supplement at $15.5 \mathrm{~h}$, the percent $\mathrm{PHB}$ value first increased gradually to $9.2 \%$ and then decreased slightly with the consumption of oxygen. Likewise, after the second oxygen supplement, the increase and decrease cycle of the PHB content was observed again. The similar behaviors were also observed at 0.2 and 0.3 atmO $\mathrm{O}_{2}$, as well. When the oxygen partial pressures were 0.4 and $0.5 \mathrm{~atm}$ (no headspace gas refreshment was performed), the PHB content was also increased at first and the maximal PHB content was obtained at $15.5 \mathrm{~h}$. But, afterward, the PHB level was decreased.

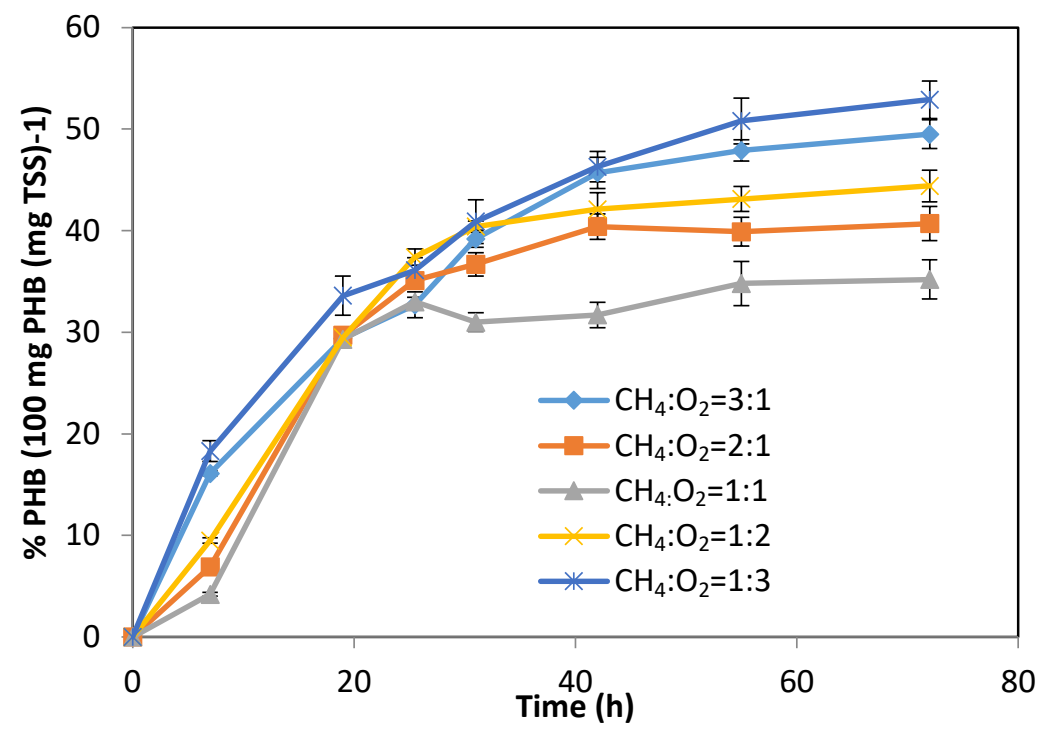

Figure 1. The time course of the percent $\mathrm{PHB}$ with the different ratios of the methane to the oxygen at constant pressure in the absence of $\mathrm{N}_{2}$.

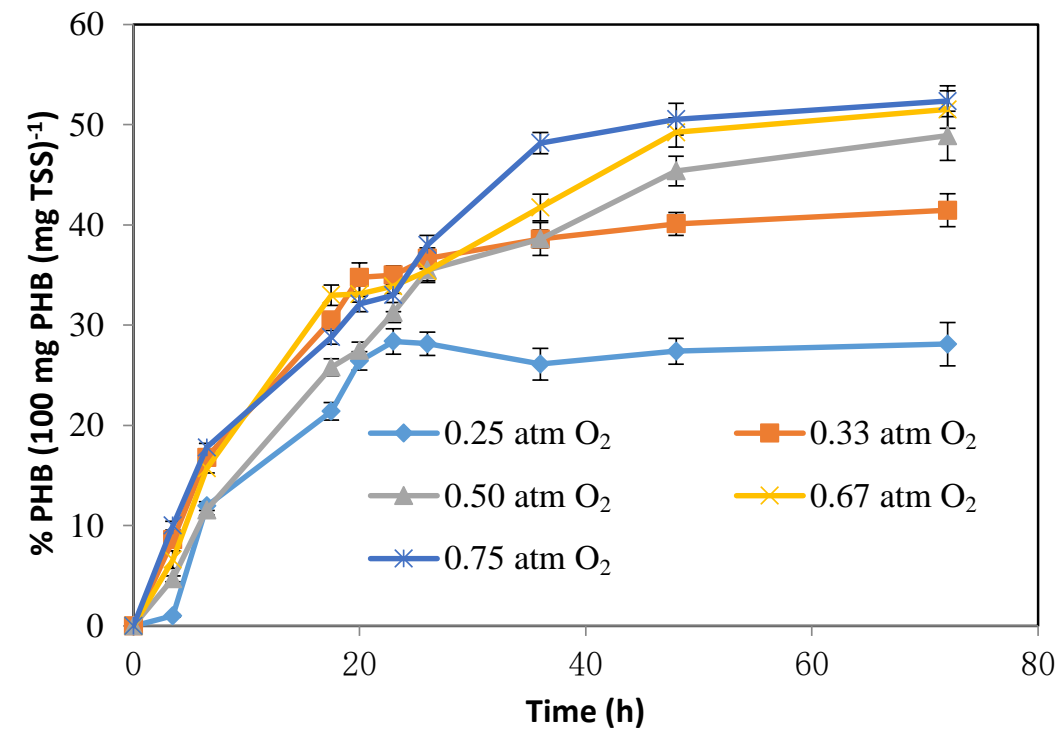

Figure 2. The profiles of the cellular PHB content at different oxygen concentrations with 0.5 atm $\mathrm{CH}_{4}$ in the absence of $\mathrm{N}_{2}$. 


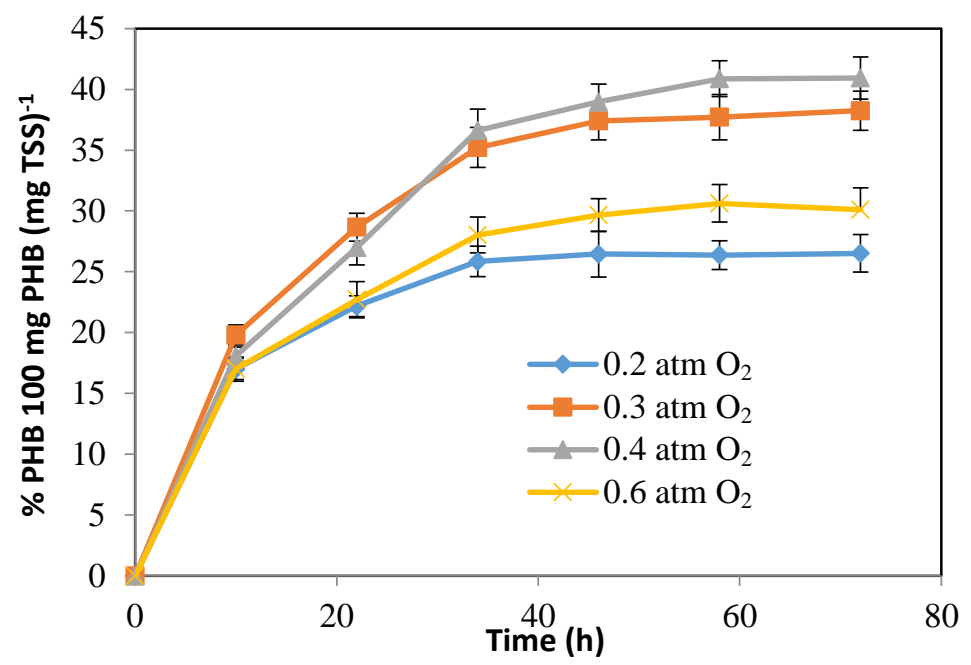

Figure 3. The time course of the percent $\mathrm{PHB}$ at different oxygen concentration with $0.2 \mathrm{~atm} \mathrm{CH}_{4}$ in the absence of $\mathrm{N}_{2}$.
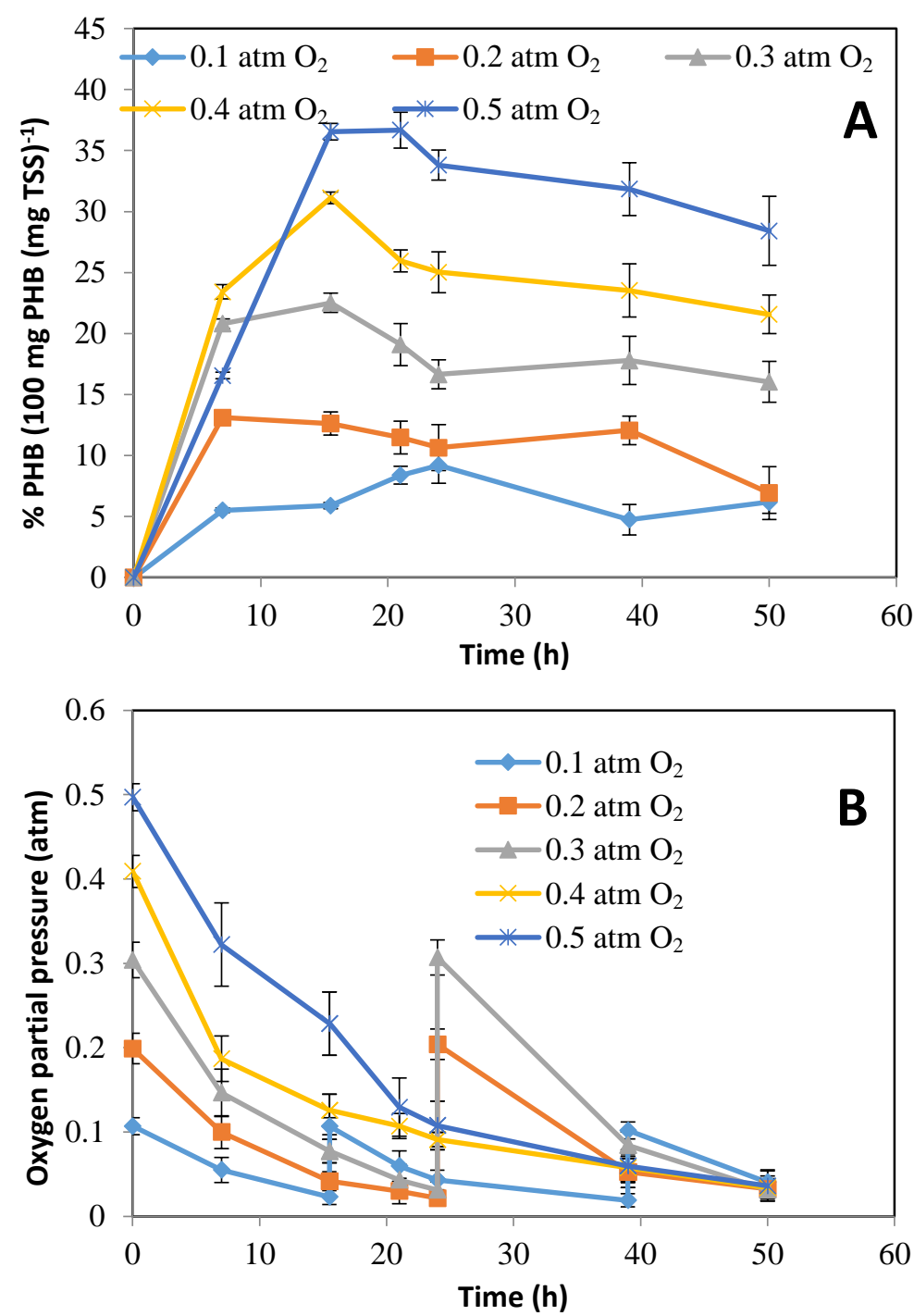

Figure 4. (A) The graph representing the variation in the percent $\mathrm{PHB}$ and (B) changes in the oxygen partial pressure in the presence of $\mathrm{N}_{2 .} 0.5$ atm $\mathrm{CH}_{4}, 0.3 \mathrm{~atm} \mathrm{~N}$ and different concentration of the $\mathrm{O}_{2}$ were introduced and the headspace was refreshed only when oxygen was almost depleted.

To test the possibility of more PHB accumulation in the presence of the $\mathrm{N}_{2}$, the headspace gas was refilled every
12 hours, as the PHB content began to decrease after that. As shown in Figure 5, the different effects of the $\mathrm{O}_{2}$ 
on PHB synthesis were observed. The highest maximal percent $\mathrm{PHB}$ value (55.5\%) was obtained at $0.2 \mathrm{~atm} \mathrm{O}_{2}$. The decrease in the maximal PHB content occurred when oxygen concentration was successively increased to $0.5 \mathrm{~atm}$ as observed in the following pattern: 0.3 $\operatorname{atmO}_{2}(47.0 \%)>0.4 \mathrm{~atm} \mathrm{O}_{2}(45.9 \%)>0.5 \mathrm{~atm}$ (37.3\%). Then, the maximal PHB content slightly increased to $40.7 \%$ when oxygen concentration was further increased to $0.7 \operatorname{atm}(\rho=-0.086, \mathrm{n}=10, \mathrm{P}=$
0.001). The inhibition of the higher concentration oxygen on $\mathrm{PHB}$ synthesis of the methanotroph appeared at $0.5 \mathrm{atmCH}_{4}$ in the presence of $\mathrm{N}_{2}$. Table 1 provides details of the maximal PHB concentration and PHB productivity obtained in the regimen of refreshed headspace gas every 12 hours. It is noteworthy that the highest $\mathrm{PHB}$ concentration of the $901.8 \mathrm{mg} . \mathrm{L}^{-1}$ was obtained at 0.2 atm $\mathrm{O}_{2}$ with a $\mathrm{PHB}$ productivity of 12.5 mg. $L^{-1} \cdot h^{-1}$.

Table 1. The maximal PHB concentration and PHB productivity obtained in the regimen of the renovating headspace every $12 \mathrm{~h}$ in presence of $\mathrm{N}_{2}$.

\begin{tabular}{ccc}
\hline Oxygen concentration $(\mathbf{a t m})$ & Maximal PHB concentration $\left(\mathbf{m g} . \mathbf{L}^{-\mathbf{1}}\right)$ & ${\text { PHB productivity }\left(\mathbf{m g}^{\mathbf{L}} \mathbf{L}^{\mathbf{1}} \cdot \mathbf{h}^{\mathbf{1}}\right)}$ \\
\hline 0.20 & $901.8 \pm 21.3$ & $12.5 \pm 0.3$ \\
0.30 & $652.1 \pm 31.4$ & $9.1 \pm 0.4$ \\
0.40 & $623.1 \pm 24.1$ & $8.7 \pm 0.3$ \\
0.50 & $443.5 \pm 19.1$ & $6.2 \pm 0.3$ \\
0.70 & $507.7 \pm 23.8$ & $7.1 \pm 0.3$ \\
\hline
\end{tabular}

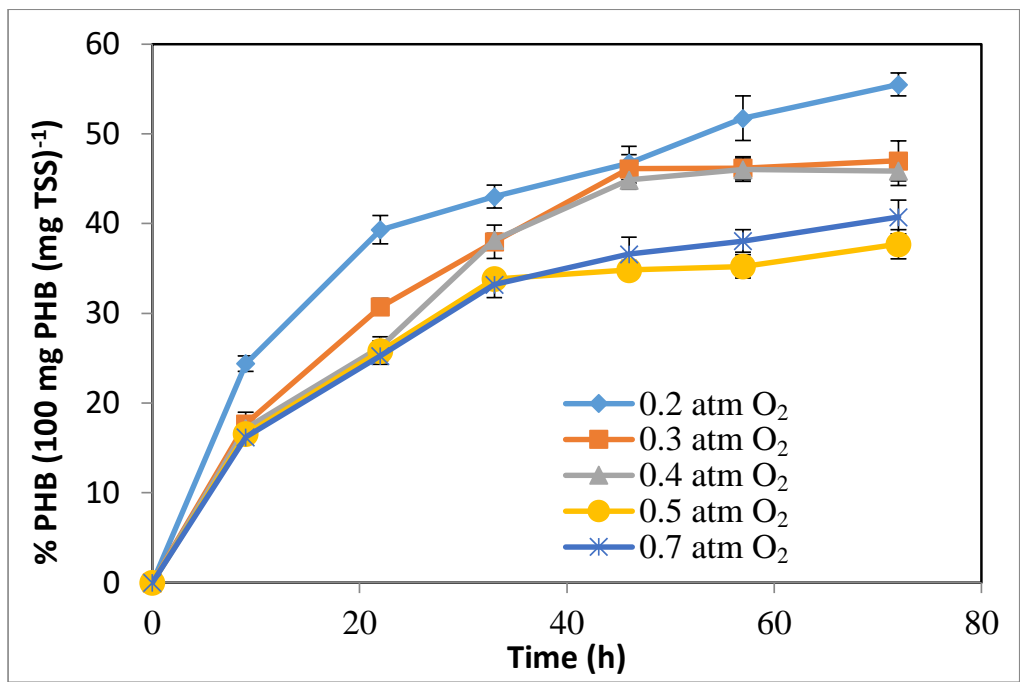

Figure 5. The effect of the oxygen concentration on PHB accumulation with headspace replenished every $12 \mathrm{~h}$ in the presence of $\mathrm{N}_{2}$. The initial headspace was consisted of the $0.5 \mathrm{~atm} \mathrm{CH}_{4}, 0.3 \mathrm{~atm} \mathrm{~N}$ and different concentration of $\mathrm{O}_{2}$.

\section{Discussion}

The PHB accumulation was first conducted with different ratios of the methane to the oxygen in the absence of $\mathrm{N}_{2}$. It has been reported that methanotrophs prefers to grow at the level where both oxygen and methane are completely consumed (21). It has been calculated that the molar ratio of the consumed methane and oxygen consumed is equal to $1: 1.5$ in theory (22). In $\mathrm{PHB}$ production phase, the higher maximal $\mathrm{PHB}$ contents were more likely to be obtained with excessive methane at the higher ratios of methane to oxygen. The result was consistent with the previous research about $\mathrm{PHB}$ production from the mixtures of the volatile fatty acids (VFAs) that, an excess exogenous carbon source is favorable for the intracellular PHA accumulation of the activated sludge (23).

At a fixed methane partial pressure without $\mathrm{N}_{2}$, the data indicated that limiting $\mathrm{O}_{2}$ concentration negatively affected the PHB accumulation of the methanotrophs, which was also verified previously (2). So, it is important to ensure adequate oxygen pressure during the accumulation of the PHB. On the other hand, it seems that an overdose of oxygen might depress PHB synthesis of the methanotroph and the oxygen partial pressure that inhibited PHB production perhaps varied at different methane partial pressure, as well. It has been reported that with oxygen concentrations increasing from $20 \%$ to $60 \%$, the methane oxidization rate was reduced by more than $23 \%$ for both types I and II methanotrophs (24). Henckel et al. reported that responses of the methane oxidation of the rice field soil to the increased oxygen concentration varies at high and low methane concentration, which is consistent with the phenomenon observed in this test (25). It has been reported that the molar ratio of the methane to that of oxygen should be maintained at a ratio $\geq 1: 2$ for an improved methane oxidation (26). In tests with $0.5 \mathrm{~atm}$ $\mathrm{CH}_{4}$, the $\mathrm{CH}_{4}: \mathrm{O}_{2}$ ratio was maintained at a ratio $\geq 1: 1.5$ and the maximal PHB content was gradually increased with an increased oxygen con centrations. However, in the tests with $0.2 \mathrm{~atm} \mathrm{CH}_{4}$, when the oxygen partial pressure was increased to $0.6 \mathrm{~atm}\left(\mathrm{CH}_{4}: \mathrm{O}_{2}=1: 3\right)$, the maximal $\mathrm{PHB}$ content was indeed significantly 
decreased. Therefore, the lower $\mathrm{PHB}$ content of $\mathrm{CH}_{4}: \mathrm{O}_{2}=1: 3$ was likely to be mainly caused by the inhibition of excess oxygen.

In the presence of $\mathrm{N}_{2}$, with the headspace gas replenished only when oxygen was almost depleted, PHB was accumulated and degraded cyclically. It has been reported that with the different mixture of the methane and air as the gaseous substrate flow, once nitrate was exhausted, the percent value of PHB was improved apparently at first and then followed by a gradual reduction which was in agreement with the phenomenon presented in these investigations (17). It has been observed that only slow growth of the methanotrophs was performed with $\mathrm{N}_{2}$ as a sole nitrogen source when compared with the nitrate- or ammonium-supplied bacteria (15), which indicated that $\mathrm{N}_{2}$ could only provide a limited source of nitrogen. It seems that regardless of the oxygen partial pressure, the sudden removal of nitrate would result in a relative lack of nitrogen source and stimulates $\mathrm{PHB}$ accumulation at the beginning even though $\mathrm{N}_{2}$ was added as a nitrogen source. It has been demonstrated that Type II methanotrophs have a complete tricarboxylic acid (TCA) cycle, which can utilize acetyl CoA produced from $\mathrm{PHB}$ degradation as the substrate to produce reducing equivalents (13). On the other hand, it is well known that a reducing equivalent is required in the process of energy-intensive $\mathrm{N}_{2}$ fixation (27). Moreover, type II nitrogenase of the methanotrophs has been reported to tolerate an oxygen partial pressure up to $28 \%$ (28). Therefore, the degradation of PHB might be used as a source of reducing power to assimilate $\mathrm{N}_{2}$.

When compared with $\mathrm{PHB}$ productions at $0.5 \mathrm{~atm} \mathrm{CH}_{4}$ without $\mathrm{N}_{2}$, the maximal $\mathrm{PHB}$ content of $0.2 \mathrm{~atm} \mathrm{O}_{2}$ was significantly improved in the presence of $\mathrm{N}_{2}$ with the headspace replenished every $12 \mathrm{~h}$, which was likely attributed to the limited nitrogen source provided by the N2 fixation. A kinetic study of the PHB production by Protomonas extorque revealed that a nitrogen source was necessary, not only in the growth phase but also in the PHB production phase, as well (29). It was reported that the PHB accumulation of a recombinant Escherichia coli was improved significantly when a small quantity of the complex nitrogen source was added (30). With oxygen concentration progressively increasing to $0.7 \mathrm{~atm}$, the maximal $\mathrm{PHB}$ content decreased obviously in the presence of $\mathrm{N}_{2}$, which was so different from results observed at $0.5 \mathrm{~atm} \mathrm{CH}_{4}$ in the absence of $\mathrm{N}_{2}$. It has been observed that the response of the methane oxidation to the increase of the oxygen concentration under $\mathrm{N}_{2}$-fixing condition was opposite to that under nitrate-supplied conditions, which was supposed to be due to the effect of nitrogen metabolism on carbon metabolism (31). So, the reverse effects of oxygen partial pressure on PHB production between tests in the presence and in the absence of $\mathrm{N}_{2}$ at $0.5 \mathrm{~atm}$
$\mathrm{CH}_{4}$ might be attributed to the variations of the carbon metabolism.

In conclusion, both in the presence and in the absence of $\mathrm{N}_{2}$, the maximal PHB content of $M$. trichosporium $\mathrm{OB}_{3} \mathrm{~b}$ could reach a high value. The responses of $\mathrm{PHB}$ accumulation of methanotroph to oxygen partial pressures in the absence of $\mathrm{N}_{2}$ were opposite to that in the presence of $\mathrm{N}_{2}$. The production of high content $\mathrm{PHB}$ in the presence of $\mathrm{N}_{2}$ would greatly reduce the requirement for the purity of the methane and pure oxygen could also be substituted by the air, leading to a further reduction in the $\mathrm{PHB}$ production cost.

\section{Acknowledgment}

We greatly appreciate M. Kalyuzhnaya of the University of Washington for providing Methylosinus trichosporium $\mathrm{OB}_{3} \mathrm{~b}$. The present investigation was supported by the Henan Postdoctoral Research Project (Chemical Absorption-Biological Treatment Integrated Process for Flue Gas Desulfurization and Denitration) and the National Key Scientific and Technology Project for Water Pollution Treatment of China (2012ZX07202006).

\section{References}

1. Akaraonye E, Keshavarz T, Roy I. Production of polyhydroxyalkanoates: the future green materials of choice. J Chem Technol Biotechnol. 2010;85(6):732-743. doi: $10.1002 /$ jctb. 2392

2. Karthikeyan OP, Chidambarampadmavathy K, Cirés S, Heimann K. Review of Sustainable Methane Mitigation and Biopolymer Production. Crit Rev Environ Sci Technol. 2014;45(15):1579-1610. doi: 10.1080/106 43389.201 4.966422

3. Khosravi-Darani K, Vasheghani-Farahani E, Shojaosadati SA, Yamini Y. Effect of process variables on supercritical fluid disruption of Ralstonia eutropha cells for poly(Rhydroxybutyrate) recovery. Biotechnol Prog. 2004;20(6):1757-1765. doi: 10.1021/bp0498037 pmid: 15575709

4. Mokhtari-Hosseini ZB, Vasheghani-Farahani E, Heidarzadeh-Vazifekhoran A, Shojaosadati SA, Karimzadeh R, Khosravi Darani K. Statistical media optimization for growth and PHB production from methanol by a methylotrophic bacterium. Bioresour Technol. 2009;100(8):2436-2443. doi: 10.1016/j.bior tech.2008.11.024 pmid: 19121581

5. Mokhtari-Hosseini ZB, Vasheghani-Farahani E, Shojaosadati SA, Karimzadeh R, HeidarzadehVazifekhoran A. Effect of feed composition on PHB production from methanol by HCDC ofMethylobacterium extorquens(DSMZ 1340). J Chem Technol Biotechnol. 2009;84(8):1136-1139. doi: $10.1002 /$ jctb. 2145

6. Park DH, Kim BS. Production of poly(3hydroxybutyrate) and poly(3-hydroxybutyrate-co-4hydroxybutyrate) by Ralstonia eutropha from soybean oil. N Biotechnol. 2011;28(6):719-724. doi: 10.1016/j.nbt.2011.01.007 pmid: 21333767

7. Tanaka K, Miyawaki K, Yamaguchi A, Khosravi-Darani K, Matsusaki $\mathrm{H}$. Cell growth and $\mathrm{P}(3 \mathrm{HB})$ accumulation 
from $\mathrm{CO} 2$ of a carbon monoxide-tolerant hydrogenoxidizing bacterium, Ideonella sp. O-1. Appl Microbiol Biotechnol. 2011;92(6):1161-1169. doi: 10.1007/s00 253-011-3420-2 pmid: 21695533

8. Lopez JC, Quijano G, Perez R, Munoz R. Assessing the influence of $\mathrm{CH} 4$ concentration during culture enrichment on the biodegradation kinetics and population structure. J Environ Manage. 2014;146:116123. doi: $10.1016 /$ j.jenvman.2014.06.026 pmid: 25169 644

9. Zuniga C, Morales M, Le Borgne S, Revah S. Production of poly-beta-hydroxybutyrate (PHB) by Methylobacterium organophilum isolated from a methanotrophic consortium in a two-phase partition bioreactor. J Hazard Mater. 2011;190(1-3):876-882. doi: 10.1016/j.jhazmat.2011.04.011 pmid: 21530080

10. Listewnik HF, Wendlandt KD, Jechorek M, Mirschel G. Process Design for the Microbial Synthesis of Poly- $\beta$ hydroxybutyrate (PHB) from Natural Gas. Eng Life Sci. 2007;7(3):278-282. doi: 10.1002/elsc.200620193

11. Rostkowski KH, Criddle CS, Lepech MD. Cradle-to-gate life cycle assessment for a cradle-to-cradle cycle: biogasto-bioplastic (and back). Environ Sci Technol. 2012;46(18):9822-9829. doi: 10.1021/es204541w pmid: 22775327

12. Khosravi-Darani K, Mokhtari Z-B, Amai T, Tanaka K. Erratum to: Microbial production of poly(hydroxybutyrate) from C1 carbon sources. Appl Microbiol Biotechnol. 2013;97(12):5657-5657. doi: 10.1007/s00253-013-4807-z

13. Pieja AJ, Sundstrom ER, Criddle CS. Poly-3hydroxybutyrate metabolism in the type II methanotroph Methylocystis parvus OBBP. Appl Environ Microbiol. 2011;77(17):6012-6019. doi: 10.1128/AEM.00509-11 pmid: 21724874

14. Strong PJ, Laycock B, Mahamud SN, Jensen PD, Lant PA, Tyson G, et al. The Opportunity for High-Performance Biomaterials from Methane. Microorganisms. 2016;4(1):11. doi: 10.3390/microorg anisms4010011 pmid: 27681905

15. Rostkowski KH, Pfluger AR, Criddle CS. Stoichiometry and kinetics of the PHB-producing Type II methanotrophs Methylosinus trichosporium OB3b and Methylocystis parvus OBBP. Bioresour Technol. 2013;132:71-77. doi: 10.1016/j.biortech.2012.12.129 pmid: 23395757

16. Chu KH, Alvarez-Cohen L. Effect of nitrogen source on growth and trichloroethylene degradation by methaneoxidizing bacteria. Appl Environ Microbiol. 1998;64(9):3451-3457. pmid: 9726896

17. Shah NN, Hanna ML, Taylor RT. Batch cultivation ofMethylosinus trichosporium OB3b: V. Characterization of poly- $\beta$-hydroxybutyrate production under methane-dependent growth conditions. Biotechnol Bioeng. 1996;49(2):161-171. doi: 10.1002/(sici)10970290(19960120)49:2<161::aid-bit5>3.0.co;2-o

18. Knief C, Dunfield PF. Response and adaptation of different methanotrophic bacteria to low methane mixing ratios. Environ Microbiol. 2005;7(9):1307-1317. doi: 10.1111/j.1462-2920.2005.00814.x pmid: 16104854
19. Chen Z, Meng H, Xing G, Chen C, Zhao Y, Jia G, et al. Acute toxicological effects of copper nanoparticles in vivo. Toxicol Lett. 2006;163(2):109-120. doi: 10.1016/j.toxlet.2005.10.003 pmid: 16289865

20. Chen Z, Li Y, Wen Q, Zhang H. Biosynthesis of polyhydroxyalkanoate by Gamma proteobacterium WD3 from volatile fatty acids. Chemosphere. 2011;82(8):1209-1213. doi: 10.1016/j.chemospher e.2010.11.030 pmid: 21129764

21. Amaral JA, Knowles R. Growth of methanotrophs in methane and oxygen counter gradients. FEMS Microbiol Lett. 1995;126(3):215-220. doi: 10.1111/j.1574-6968. 1995.tb07421.x

22. Asenjo JA, Suk JS. Microbial Conversion of Methane into poly- $\beta$-hydroxybutyrate (PHB): Growth and intracellular product accumulation in a type II methanotroph. $J$ Ferment Technol. 1986;64(4):271-278. doi: 10.1016/0385-6380(86)90118-4

23. Jiang Y, Chen Y, Zheng X. Efficient polyhydroxyalkanoates production from a waste-activated sludge alkaline fermentation liquid by activated sludge submitted to the aerobic feeding and discharge process. Environ Sci Technol. 2009;43(20):7734-7741. doi: 10.1021/es9014458 pmid: 19921887

24. Ren T, Amaral JA, Knowles R. The response of methane consumption by pure cultures of methanotrophic bacteria to oxygen. Can J Microbiol. 1997;43(10):925-928. doi: $10.1139 / \mathrm{m} 97-133$

25. Henckel T, Roslev P, Conrad R. Effects of $\mathrm{O} 2$ and $\mathrm{CH} 4$ on presence and activity of the indigenous methanotrophic community in rice field soil. Environ Microbiol. 2000;2(6):666-679. doi: 10.1046/j.14622920.2000.00149.x pmid: 11214799

26. Scheutz C, Kjeldsen P, Bogner JE, De Visscher A, Gebert $\mathrm{J}$, Hilger HA, et al. Microbial methane oxidation processes and technologies for mitigation of landfill gas emissions. Waste Manag Res. 2009;27(5):409-455. doi: 10.1177/0734242X09339325 pmid: 19584243

27. Orme-Johnson WH. Molecular basis of biological nitrogen fixation. Annu Rev Biophys Biophys Chem. 1985;14(1):419-459. doi: 10.1146/annurev.bb.14.060 185.002223 pmid: 3890886

28. De Bont JAM, Mulder EG. Nitrogen Fixation and Cooxidation of Ethylene by a Methane-utilizing Bacterium. J Gen Microbiol. 1974;83(1):113-121. doi: 10.1099/00221287-83-1-113

29. Suzuki T, Yamane T, Shimizu S. Kinetics and effect of nitrogen source feeding on production of poly-?hydroxybutyric acid by fed-batch culture. Appl Microbiol Biotechnol. 1986;24(5):366-369. doi: 10.1007/bf00294591

30. Yup Lee S. Poly(3-hydroxybutyrate) production from xylose by recombinant Escherichia coli. Bioproc Eng. 1998;18(5):397. doi: 10.1007/s004490050462

31. Toukdarian AE, Lidstrom ME. Nitrogen metabolism in a new obligate methanotroph, 'Methylosinus' strain 6. J Gen Microbiol. 1984;130(7):1827-1837. doi: 10.1099/00221287-130-7-1827 pmid: 6432952 